\title{
Apyrase treatment prevents ischemia-reperfusion injury in rat lung isografts
}

\author{
Seiichiro Sugimoto, MD, PhD, ${ }^{\mathrm{a}}$ Xue Lin, MD, ${ }^{\mathrm{a}}$ Jiaming Lai, $\mathrm{MD},{ }^{\mathrm{a}}$ Mikio Okazaki, MD, $\mathrm{PhD},{ }^{\mathrm{a}}$ \\ Nitin A. Das, MD, ${ }^{\text {a }}$ Wenjun Li, MD, ${ }^{\text {a }}$ Alexander S. Krupnick, MD, ${ }^{a}$ Ridong Chen, PhD, ${ }^{b}$ \\ Soon Seog Jeong, PhD, ${ }^{\mathrm{b}}$ G. A. Patterson, MD, ${ }^{\mathrm{a}}$ Daniel Kreisel, MD, PhD, ${ }^{\mathrm{a}}$ and Andrew E. Gelman, $\mathrm{PhD}^{\mathrm{a}}$
}

\begin{abstract}
Objective: Endothelial cells express the ectoenzyme ectonucleoside adenosine triphosphate diphosphohydrolase, an apyrase that inhibits vascular inflammation by catalyzing the hydrolysis of adenosine triphosphate and adenosine diphosphate. However, ectonucleoside adenosine triphosphate diphosphohydrolase expression is rapidly lost following oxidative stress, leading to the potential for adenosine triphosphate and related purigenic nucleotides to exacerbate acute solid organ inflammation and injury. We asked if administration of a soluble recombinant apyrase APT102 attenuates lung graft injury in a cold ischemia reperfusion model of rat syngeneic orthotopic lung transplantation.
\end{abstract}

\begin{abstract}
Methods: Male Fisher 344 donor lungs were cold preserved in a low-potassium dextrose solution in the presence or absence of APT102 for 18 hours prior to transplantation into syngeneic male Fisher 344 recipients. Seven minutes after reperfusion, lung transplant recipients received either a bolus of APT102 or vehicle (saline solution). Four hours after reperfusion, APT102- and saline solution-treated groups were evaluated for lung graft function and inflammation.
\end{abstract}

Results: APT102 significantly reduced lung graft extracellular pools of adenosine triphosphate and adenosine diphosphate, improved oxygenation, and protected against pulmonary edema. Apyrase treatment was associated with attenuated neutrophil graft sequestration and less evidence of tissue inflammation as assessed by myeloperoxidase activity, expression of proinflammatory mediators, and numbers of apoptotic endothelial cells.

Conclusions: Administration of a soluble recombinant apyrase promotes lung function and limits the tissue damage induced by prolonged cold storage, indicating that extracellular purigenic nucleotides play a key role in promoting ischemia-reperfusion injury following lung transplantation.

Ischemia-reperfusion injury (IRI) continues to be a major postoperative complication following lung transplantation and is linked to shortened graft survival. ${ }^{1}$ A common feature of lung graft IRI is increased vascular permeability and microvascular damage. ${ }^{2}$ Central to the development of IRI is adhesion and eventual sequestration of activated leukocytes through disrupted endothelium. Vascular endothelial cells (ECs) are a major target of preservation damage and have been implicated in microcirculatory disturbances posttransplantation. ${ }^{3}$ Upon activation, quiescent EC are capable of altering the anticoagulant surface phenotype to one that is prothrombotic, leading to vascular occlusion. EC can interact with complement, chemokine, and humoral components.

From the Division of Cardiothoracic Surgery, Department of Surgery, ${ }^{a}$ Washington University School of Medicine, and APT Therapeutics Inc, ${ }^{\text {b }}$ St Louis, Mo.

This work was sponsored by a NIH SBIR grant (1R42HL087456) from the National Heart, Lung and Blood Institute.

S. Sugimoto and X. Lin have contributed equally to this work.

Received for publication Nov 7, 2008; revisions received March 27, 2009; accepted for publication April 23, 2009; available ahead of print July 13, 2009.

Address for reprints: Andrew E. Gelman, PhD, Assistant Professor of Surgery, Pathology \& Immunology, Campus Box 8234, 660 South Euclid Avenue, Washington University in St Louis, St Louis, MO 63110-1013 (E-mail: gelmana@wudosis. wustl.edu).

J Thorac Cardiovasc Surg 2009;138:752-9

$0022-5223 / \$ 36.00$

Copyright (c) 2009 by The American Association for Thoracic Surgery doi:10.1016/j.jtcvs.2009.04.049
They also express receptors for leukocytes, generate and respond to cytokines, present alloantigen or xenoantigen, thus modulating local immune reactions at inflammatory sites. Neutrophil sequestration and activation, in particular, seem to play a key role in vascular injury through EC adhesiondependent release of inflammatory mediators such as tumor necrosis factor (TNF)- $\alpha$ as well as proteases and reactive oxygen species. ${ }^{4}$ The functional significance of vascular injury is well documented, but the mechanisms that initiate the process remain unclear.

Previous work has shown that extracellular adenosine triphosphate (ATP) and adenosine diphosphate (ADP) are early stimulators of inflammatory responses by ECs. ${ }^{5}$ Interestingly, ATP and ADP are released in high concentrations by activated ECs and platelets following aggregation on endothelium. ${ }^{6}$ In turn, this activity further catalyzes additional platelet aggregation, leading to microthrombus formation and the eventual worsening of endothelial injury. ${ }^{5}$ Extracellular purigenic nucleotides can also directly stimulate inflammatory responses in ECs themselves as well as in macrophages and neutrophils through engagement of purigenic nucleotide receptors that stimulate the expression of inflammatory mediators and leukocyte adhesion molecules. ${ }^{7-9}$

The proinflammatory effects mediated by ATP and ADP release are negatively regulated by CD39 (ectonucleoside 


$$
\begin{aligned}
& \text { Abbreviations and Acronyms } \\
& \text { ADP = adenosine diphosphate } \\
& \text { ATP = adenosine triphosphate } \\
& \mathrm{BAL}=\text { bronchoalveolar lavage } \\
& \text { CD39 = ectonucleoside triphosphate } \\
& \text { diphosphohydrolase-1 } \\
& \text { EBD }=\text { Evans blue dye } \\
& \mathrm{EC}=\text { endothelial cell } \\
& \text { ELISA }=\text { enzyme-linked immunosorbent assay } \\
& \mathrm{IgG}=\text { immunoglobulin } \mathrm{G} \\
& \text { IL-1 } \beta=\text { inteleukin- } 1 \beta \\
& \text { IRI }=\text { ischemia-reperfusion injury } \\
& \text { MIP-2 = macrophage inflammatory protein-2 } \\
& \text { MPO = myeloperoxidase } \\
& \text { PBS = phosphate-buffered saline } \\
& \text { TNF- } \alpha=\text { tumor necrosis factor- } \alpha \\
& \text { TUNEL }=\text { terminal deoxynucleotidyl transferase } \\
& \text { dUTP nick end labeling }
\end{aligned}
$$

triphosphate diphosphohydrolase-1), an apyrase that is highly expressed on the EC membrane. ${ }^{10,11} \mathrm{CD} 39$, through its intrinsic apyrase activity, rapidly hydrolyzes extracellular ATP and ADP to adenosine monophosphate and ultimately adenosine. Interestingly, CD39 activity is quickly lost following oxidative stress. ${ }^{10}$ Moreover, CD39-deficient mice are significantly more susceptible to heart, intestinal, and kidney IRI induced by arterial occlusion. ${ }^{12-14}$ In all of these cases, organ injury is associated with increased vascular permeability, suggesting a critical role for apyrases in maintaining graft homeostasis following reperfusion after periods of warm ischemia. However, it is not clear if maintaining apyrase activity in solid organs following cold ischemia, as is necessary for organ preservation and storage during the process of transplantation, is protective against IRI.

As duration of cold ischemia time has been linked to graft survival, we asked if augmentation of CD39 enzymatic activity via the infusion of a recombinant soluble apyrase, APT102, attenuates rat lung graft IRI following prolonged cold storage and syngeneic orthotopic lung transplantation. ${ }^{1}$ Here we show for the first time that supplementing apyrase activity in a solid organ graft following prolonged cold ischemia improves graft function and attenuates inflammation in the perioperative reperfusion period. APT102-treated lung graft recipients were significantly less susceptible to pulmonary edema and had better lung graft function as compared with recipients treated with a saline vehicle.

\section{MATERIALS AND METHODS}

\section{Animals and Reagents}

Fischer 344 rats (Harlan Sprague Dawley, Inc, Indianapolis, Ind), weighing 250 to $300 \mathrm{~g}$, were used in all experiments. The Animal Studies Committee at Washington University School of Medicine approved all animal procedures.
Animals received humane care in compliance with the "Principles of Laboratory Animal Care" formulated by the National Society for Medical Research and the "Guide for the Care and Use of Laboratory Animals" prepared by the National Academy of Sciences and published by the National Institutes of Health. APT102, a recombinant soluble form of the human ecto-ATP diphosphohydrolase CD39L3, was a gift from APT Therapeutics (St Louis, Mo).

\section{Orthotopic Left Lung Transplantation and APT102 Treatment}

To conduct orthotopic left lung transplantation, we used a previously described cuff technique. ${ }^{15}$ In brief, after general anesthesia with intraperitoneal pentobarbital $(65 \mathrm{mg} / \mathrm{kg})$, mechanical ventilation, systemic heparinization $(300 \mathrm{U})$, and median laparosternotomy, donor rat lungs were flushed through the main pulmonary artery with $20 \mathrm{~mL}$ of cold $\left(4^{\circ} \mathrm{C}\right)$ low-potassium dextran glucose solution at $20 \mathrm{~cm} \mathrm{H}_{2} \mathrm{O}$ pressure. In APT102-treated groups, $0.1 \mathrm{mg} / \mathrm{L}$ APT102 was added to the cold preservation medium. The heart-lung block was then removed with the lungs inflated at end-tidal volume. The left lung graft was isolated, prepared, and stored in low-potassium dextran glucose at $4{ }^{\circ} \mathrm{C}$ until transplantation. After 18 hours of cold preservation, recipient animals were anesthetized and intubated with a 14-gauge catheter, and we performed a left thoracotomy. The pulmonary vessels and bronchus were anastomosed with a standard cuff technique. In the sham group, rats received anesthesia and thoracotomy alone. In APT102-treated groups, recipients received treatment intravenously through the internal jugular vein 7 minutes after graft reperfusion. In dose-response studies, APT102 was administered at a dose of 0.07 , 0.22 , or $0.66 \mathrm{mg} / \mathrm{kg}$ of recipient weight. In all other studies, APT102 was administered at a dose of $0.66 \mathrm{mg} / \mathrm{kg}$ of recipient weight. In the vehicle-treated groups, rats received a saline bolus 7 minutes after reperfusion.

\section{Functional Assessment of Transplanted Lung Grafts}

The function of the left lung was assessed 4 hours after transplantation. Rats in each group were reanesthetized with pentobarbital. After tracheostomy, the animals were mechanically ventilated with $100 \%$ oxygen, and we performed a laparosternotomy. The right hilar structures were clamped to isolate the left lung graft. The animals were ventilated for 5 minutes at a tidal volume of $1.5 \mathrm{~mL}$, a respiratory rate of 100 breaths/min, and $1.0 \mathrm{~cm} \mathrm{H}_{2} \mathrm{O}$ of positive end-expiratory pressure. Arterial blood gas analysis was performed with blood samples obtained from the ascending aorta. The lungs were flushed with $20 \mathrm{~mL}$ of cold $\left(4^{\circ} \mathrm{C}\right)$ saline solution, and the lung graft was excised and divided into 3 separate sections. The upper and middle sections were snap frozen. The upper section was used for enzyme-linked immunosorbent assay (ELISA) and the middle section was used for myeloperoxidase (MPO) assay. The lower section was weighed, dried at $70^{\circ} \mathrm{C}$ for 48 hours, and then reweighed for calculation of the wet-to-dry ratio.

\section{Real-Time Polymerase Chain Reaction}

Total RNA was isolated by Trizol (Sigma, St Louis, Mo) from lung tissue in accordance with manufacturer's recommendations and reverse transcribed and amplified using QuantiTect SYBR RT-PCR kit (Qiagen, Valencia, Calif) and primer sets (Qiagen) specific for Rattus norvegicus Entpd2 (CD39) and the housekeeping gene Rn18s (18sRNA). Reverse-transcriptase polymerase chain reaction was carried out on a Bio Rad ICycler for 30minutes at $50^{\circ} \mathrm{C}, 15$ minutes at $95^{\circ} \mathrm{C}$, and then 40 cycles of $95^{\circ} \mathrm{C}$ for 15 seconds, $58^{\circ} \mathrm{C}$ for 30 seconds, and $72^{\circ} \mathrm{C}$ for 30 seconds. Levels of intragraft CD39 were calculated by the $\mathrm{DDC}_{\mathrm{T}}$ method using 18sRNA as a relative standard and represented through normalizing CD39 mean expression to CD39 mean expression in resting lung tissue.

\section{Flow Cytometry}

Lungs were digested in a RPMI 1640 solution containing type 2 collagenase $(0.5 \mathrm{mg} / \mathrm{mL})$ (Worthington Biochemical Corporation, Lakewood, $\mathrm{NJ}$ ) and $5 \mathrm{U} / \mathrm{mL}$ DNAse (Sigma) for 60 minutes. The digested lung tissue was 
then passed through a 70- $\mu \mathrm{m}$ cell strainer and treated with ACK lysing buffer. Cells were then stained with biotinylated anti-rat CD31 along with either goat-anti rat E-selectin (R\&D Systems, Minneapolis, Minn) or a goat immunoglobulin control immunoglobulin G (IgG; Ebiosciences, San Diego, Calif). Samples were then washed and stained with hamster anti-goat IgG phycoerythrin (Invitrogen, Carlsbad, Calif) and anti-biotin APC-750 (Ebiosciences) and then analyzed for EC-specific E-selectin expression on a modified 5-color Becton Dickinson FACS Scan (Becton Dickinson, Franklin Lakes, NJ) using a CD $31^{+}$expression gate.

\section{ATP/ADP Assay}

Aliquots from $5.0 \mathrm{~mL}$ bronchoalveolar fluid samples were assayed for ATP and ADP using EnzyLight ATP and ADP assay kits (BioAssay Systems) in accordance with manufacturer's recommendations.

\section{Myeloperoxidase Activity}

Quantitative MPO activity was determined as previously described. ${ }^{16}$ Optical density was measured at $460 \mathrm{~nm}$ with a spectrophotometer (model PMQ II; Carl Zeiss, Oberkochen, Germany). Color development was linear from 5 to 20 minutes. One unit of enzyme activity was defined as 1.0 optical density unit per minute per milligram of tissue protein at room temperature.

\section{Proinflammatory Cytokine and Chemokine Measurement}

Lung samples were homogenized with T-PER Extraction Reagent (Pierce, Rockford, Ill). Lung homogenates were centrifuged twice at $10,000 \mathrm{rpm}$ at $4^{\circ} \mathrm{C}$ for 5 minutes, and the supernatants were collected. The content of TNF- $\alpha$, inteleukin (IL)-1 $\beta$, and macrophage inflammatory protein-2 (MIP-2) were determined by using ELISA kits (BioSource International, Inc, Camarillo, Calif) in accordance with manufacturer's instructions.

\section{Evans Blue Dye Exclusion Analysis}

Evans blue dye (EBD) was used to determine lung microvascular permeability. EBD is a sensitive marker for pulmonary edema, and microvascular dysfunction was quantified by measuring the concentration of EBD within the lung. EBD solution $(100 \mathrm{mg} / \mathrm{mL})$ was prepared in phosphate-buffered saline solution (PBS; $\mathrm{pH} 7.4)$. A separate series of animals $(\mathrm{n}=5$ each) had the same surgical procedure and received EBD solution $(30 \mathrm{mg} / \mathrm{kg})$ intravenously 5 minutes after reperfusion. Four hours after reperfusion, lung grafts were excised and snap frozen following flushing with $20 \mathrm{~mL}$ of PBS. To extract EBD, the lung tissue was homogenized in $5 \mathrm{~mL}$ of formamide. The homogenate was incubated at $37^{\circ} \mathrm{C}$ for 24 hours and centrifuged at $3500 \mathrm{~g}$ for 30 minutes. The optical density of the supernatant was measured at $620 \mathrm{~nm}$. The concentration of EBD was calculated from a standard curve of EBD-formamide solutions and expressed as milligrams of EBD per gram of wet lung weight.

\section{Bronchoalveolar Lavage}

A separate series of animals ( $n=5$ each) underwent bronchoalveolar lavage (BAL) cell counts at the time of sacrifice. The right hilum was clamped, and the left lung was lavaged twice with saline ( $3.0 \mathrm{~mL}$ per lavage) through the tracheostomy. BAL fluid was centrifuged at $1500 \mathrm{rpm}$ for 8 minutes. The pellet was resuspended in PBS, and total cell numbers were counted with hemocytometer using Trypan blue solution (Mediatech, Herndon, Va) to exclude dead cells. Neutrophil numbers were determined with a Hemovet HV950FS (CDC Technologies, Oxford, Conn).

\section{Terminal Deoxynucleotidyl Transferase dUTP Nick End Labeling Assay}

Lung specimens harvested 4 hours after reperfusion were perfused with $20 \mathrm{~mL}$ isotonic sodium chloride solution and inflation fixed with $20 \mathrm{~mL}$ HistoChoice (Amresco Inc, Solon, Ohio). Specimens were cut, mounted, deparaffinized, and then steam treated with Dako target retrieval solution (Dako,
Carpinteria, Calif) and quenched with 3\% hydrogen peroxide. Assessment of lung cell apoptosis was performed with a terminal deoxynucleotidyl transferase dUTP nick end labeling (TUNEL) kit (Promega, Madison, Wis) in accordance with manufacturer's instructions. For quantification of cell apoptosis, 15 randomly chosen fields were assessed for each group at a magnification of $\times 400$.

\section{Statistical Analysis}

Experimental means are represented with the standard error of the mean. Statistical analysis to assess significant differences between experimental groups was performed by using the Student $t$ test.

\section{RESULTS \\ APT102 Treatment Protects Against Lung Graft IRI}

Prior studies have shown that CD39 is required to protect against solid organ injury and inflammation. ${ }^{5}$ We asked if CD39 expression is maintained in lung grafts in a rat model of lung graft IRI. Lung isografts underwent 18 hours of cold preservation prior to engraftment and were measured for intragraft CD39 mRNA 1 or 4 hours after transplantation (Figure 1, A). Lung grafts from recipients following either 1 or 4 hours of reperfusion had significantly less intragraft CD39 transcripts relative to either lung tissue preserved for 18 hours prior to transplantation or lung tissue obtained from sham-operated rats. As these data suggested that there is a loss of ectoapyrase activity following lung transplantation, we next asked if administration of APT102, a soluble recombinant apyrase, affects lung function and injury in our model (Figure 1, B). Prior to 18 hours of cold preservation, either lung grafts were flushed with APT102 $(0.1 \mathrm{mg} / \mathrm{mL})$ or vehicle (saline) and then graded amounts of APT102 or a bolus of saline was administered intravenously 7 minutes following reperfusion. Compared with saline solution-treated recipients, APT102-treated recipients showed a trend toward better lung function at a dose of $0.22 \mathrm{mg} / \mathrm{kg}$ and significant improvement at a dose of $0.66 \mathrm{mg} / \mathrm{kg}$. In accordance with improved lung function, pulmonary edema trended to lower mean levels at a 0.22 $\mathrm{mg} / \mathrm{kg}$ dose of APT102 and was significantly attenuated at a $0.66 \mathrm{mg} / \mathrm{kg}$ dose of APT102 (Figure 1, $C$ and $D$ ). We next asked if the APT102-mediated effects on lung graft IRI were associated with apyrase-specific activity by assessing the concentration of extracellular purigenic nucleotides (Figure 2). BAL fluid was obtained from saline solutiontreated or APT102-treated recipients and measured for ATP and ADP levels. Relative to saline solution-treated lung graft recipients, APT102-treated lung graft recipients had significantly lower concentrations of both ATP and ADP in the BAL fluid, indicating that augmenting apyrase-specific activity helps preserve lung graft function.

\section{APT102 Treatment Inhibits the Sequestration of Neutrophils in Lung Grafts}

Lung graft IRI is exacerbated by the rapid accumulation of neutrophils in the airways and lung interstitium. ${ }^{2} \mathrm{We}$ 
A

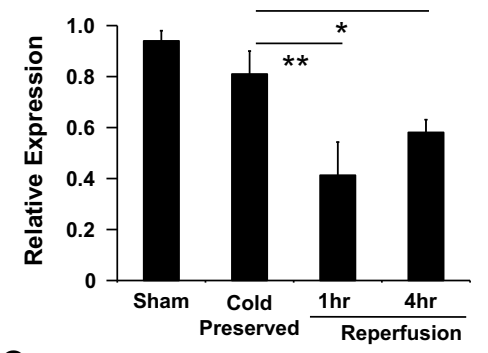

C

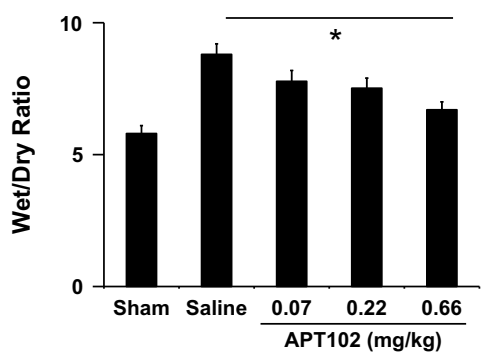

B
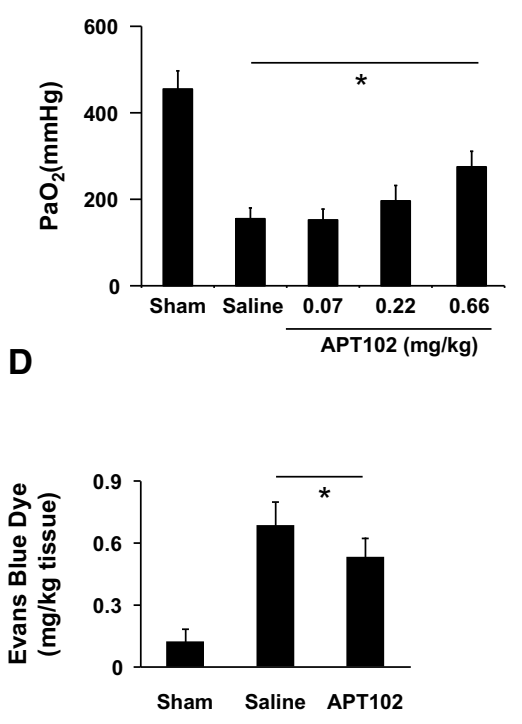

FIGURE 1. APT102 treatment improves lung function and attenuates vascular permeability following lung transplantation. A, Sham lungs, 18-hour coldpreserved lungs, or lung graft tissue following 1 or 4 hours of reperfusion were assessed for CD39 transcripts by semiquantitative reverse-transcriptase polymerase chain reaction and represented as normalized to CD39 levels in resting lung tissue. Sham animals or lung graft recipients treated with saline solution or indicated amounts of APT102 4 hours postreperfusion were assessed for (B) arterial blood gasses at $\mathrm{FiO}_{2} 1.0$ expressed as a mean $\mathrm{Po}_{2}(\mathrm{~mm} \mathrm{Hg})$ or $(\mathrm{C})$ mean wet-to-dry weight ratio. D, Mean percent exclusion of Evans blue dye in sham lungs or lung grafts treated with $0.66 \mathrm{mg} / \mathrm{kg}$ APT102 or saline 4 hours postreperfusion. Results (A-D) are representative of at least 5 recipients per group and expressed as means \pm standard errors of the mean. $* P<.05$ or $* * P<.01$ between indicated groups.

therefore asked if APT102-mediated improvement of lung graft function was associated with the regulation of inflammatory cell trafficking into lung grafts. Lung isografts were cold preserved for 18 hours before engraftment, and total cell accumulation along with neutrophil numbers in the BAL were assessed 4 hours after transplantation. APT102treated lung graft recipients had significantly fewer cells in the BAL (Figure 3, A). Additionally, we observed a significant decrease in the numbers of neutrophils recovered from the airways of APT102-treated lung graft recipients as compared with saline solution-treated lung graft recipients (Figure 3,B). MPO activity, a relative measure of neutrophil graft tissue infiltration, was also reduced in lung grafts of
APT102-treated recipients along with the expression of E-selectin, a critical marker of EC activation that promotes neutrophil adhesion and sequestration ${ }^{17}$ (Figure $3, C$ and $D$ ).

\section{APT102 Treatment Attenuates Intragraft Proinflammatory Cytokine and Chemokine Synthesis}

The reduction in neutrophil accumulation in lung grafts of APT102-treated recipients suggested attenuation of intragraft inflammatory gene expression. In particular, the inflammatory cytokines TNF- $\alpha$ and IL- $1 \beta$ promote EC activation, and the chemokine MIP-2 drives neutrophil chemotaxis into graft tissue. ${ }^{2}$ We investigated if APT102 treatment regulated
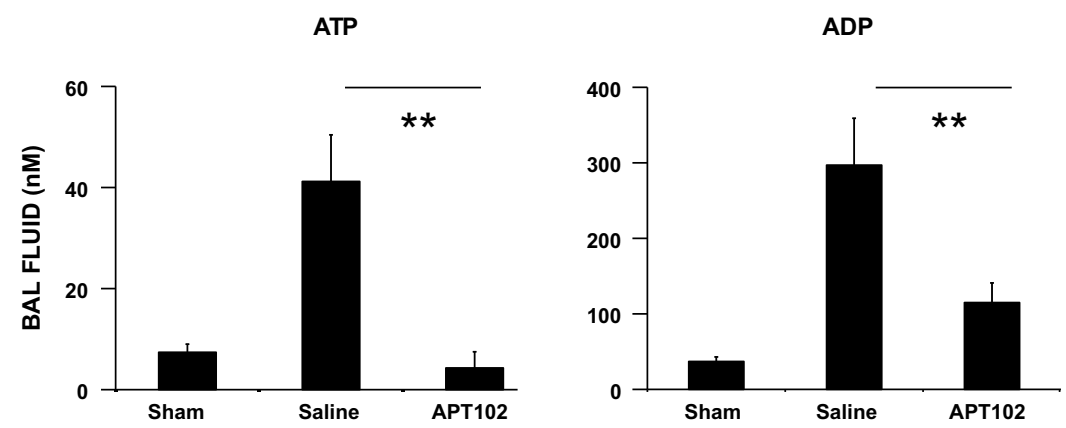

FIGURE 2. APT102 reduces adenosine triphosphate $(A T P)$ and adenosine diphosphate $(A D P)$ in lung graft airways. Bronchoalveolar lavage fluid from sham lungs or lung grafts 4 hours after engraftment were assessed for ATP and ADP concentration by bioluminescence assay. Results are representative of at least 4 recipients per group and are expressed as means \pm standard errors of the mean. $* * P<.01$ between indicated groups. 
A

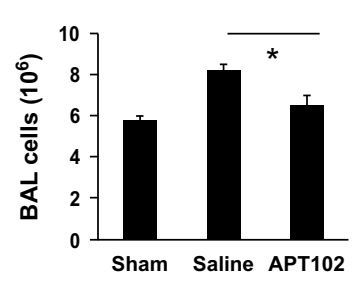

B

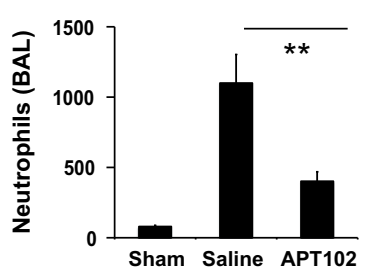

C

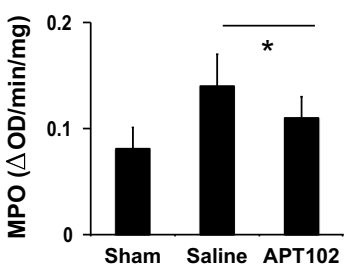

D
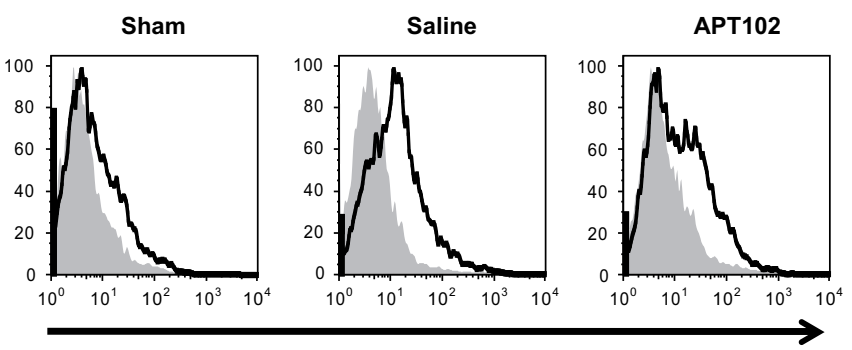

E-selectin

FIGURE 3. APT102 treatment prevents inflammatory cell sequestration and endothelial cell (EC) activation. Bronchoalveolar lavage (BAL) cells from sham lungs or lung grafts 4 hours after reperfusion were assessed for (A) total number of cells and (B) neutrophil numbers. C, Lung tissue from sham animals or lung grafts following 4 hours of reperfusion were homogenized and assessed for myeloperoxidase (MPO) activity. Results (A-C) are representative of at least 5 animals per group and expressed as a mean \pm standard error of the mean. $* P<.05$ or $* * P<.01$ for indicated groups. D, Tissue from sham animals or lung graft recipients 4 hours postreperfusion were digested and assessed for E-selectin expression on ECs by flow cytometric analysis using E-selectin and CD31-specific antibodies. Data are represented through a CD $31^{+}$expression gate by histograms depicting E-selectin expression (dark lines) relative to an isotype control (shaded).

the intragraft expression of these inflammatory mediators following 18 hours of cold ischemia and 4 hours engraftment (Figure 4). APT102 significantly attenuated the intragraft levels of TNF- $\alpha$, IL-1 $\beta$, and MIP-2 protein, suggesting that augmentation of apyrase activity down-regulates gene expression associated with tissue inflammation.

\section{APT102 Improves Graft Histopathology and Inhibits EC Apoptosis}

Previous studies have shown that limiting intragraft inflammation is important to maintaining graft architecture. $^{18,19}$ Thus, we inquired if APT102 treatment improved lung graft histopathology (Figure 5). By hemotoxylin and eosin stain, APT102-treated recipients had less apparent alveolar hemorrhage and microvascular injury as compared with saline solution-treated recipients and only minimal changes in graft architecture when compared with shamoperated lungs. These data suggested that the EC barrier is better preserved in APT102-treated recipients. To examine this further, we examined lung grafts for the presence of apoptotic EC by TUNEL stain (Figure 6, A). Consistent with previous observations in lung grafts subjected to prolonged cold ischemia, there were many apoptotic ECs in the lung graft alveoli of saline solution-treated recipients..$^{20,21}$ In contrast, in the lung grafts of APT102-treated recipients, there were significantly fewer apoptotic ECs, indicating effective protection against vascular injury (Figure 6, $B$ ).

\section{DISCUSSION}

To our knowledge, this is the first report of the evaluation of a soluble apyrase in a model of solid organ transplantation where IRI is initiated by extended cold preservation time. Extended cold ischemia time has been linked to worse lung graft survival. ${ }^{1}$ This issue is clinically relevant as donor lung shortage often necessitates procurement at geographically distant sites. Here we report that treatment with a recombinant apyrase can attenuate lung graft IRI. APT102 administration just following reperfusion is effective at improving $\mathrm{PaO}_{2}$, inhibiting pulmonary edema as well as attenuating other markers of physiologic lung injury when compared with saline solutiontreated lung transplant recipients.

A key activity of an ectoapyrase is the prevention of vascular injury through catalyzing the hydrolysis of proinflammatory extracellular purigenic nucleotides. ${ }^{10}$ The mechanisms by which apyrase administration protects against vascular injury are likely to be mediated by at least two distinct pathways: first, through preventing cell death as extracellular ATP can promote apoptosis through agonizing putative type- $2 \mathrm{X}$ purinergic (P2X7) receptors on EC, and second, through inhibiting the neutrophil sequestration by preventing the up-regulation E-selectin., ${ }^{7,22,23} \mathrm{We}$ observed a precipitous loss of CD39 expression along with a severalfold concentration increase of purigenic nucleotides in the BAL fluid from lung grafts subjected to prolonged cold ischemia and 4 hours reperfusion, thus predisposing 

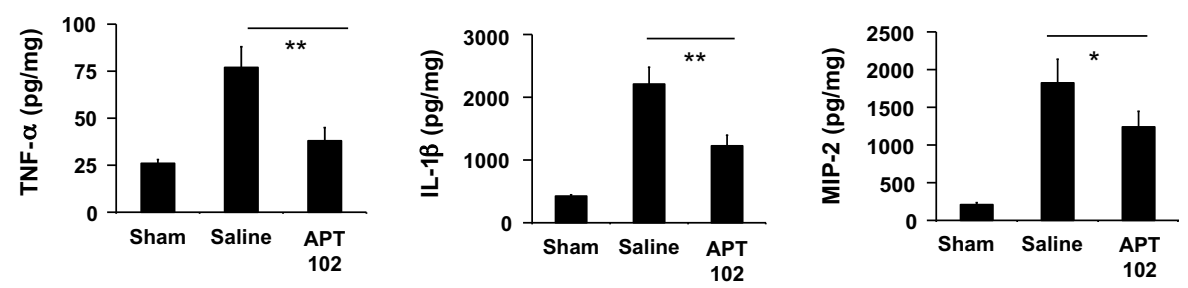

FIGURE 4. APT102 treatment inhibits inflammatory cytokines and chemokine production. Lung grafts following 4 hours of reperfusion or sham lungs were homogenized for total protein and assessed for intragraft tumor necrosis factor- $\alpha(T N F-\alpha)$, interleukin-1 $\beta(I L-1 \beta)$, and macrophage inflammatory protein-2 $(M I P-2)$ levels by enzyme-linked immunosorbent assay. Results are representative of at least 5 animals per group and expressed as mean \pm standard error of the mean. $* P<.05$ and $* * P<.01$ for indicated groups.

the lung to pulmonary vascular injury. Depletion of ATP and ADP in the BAL fluid after treatment with APT102 indicates that we were able to increase apyrase activity within lung grafts. Moreover, supplementation of apyrase activity was coincident with the prevention of deleterious vascular injury as evidenced by APT102-mediated attenuation of pulmonary edema, EC apoptosis, and alveolar hemorrhage. Additionally, we observed that APT102 treatment inhibited the expression of E-selectin on lung graft ECs. Reduction of E-selectin on ECs was also associated with significantly less intragraft accumulation of neutrophils, consistent with previous work and demonstrating a key role for this vascular activation marker on neutrophil accumulation in the setting of lung graft transplantation. ${ }^{24}$ These data collectively suggest that maintenance of apyrase activity following lung transplantation is critical to protecting the EC barrier from injury as well, attenuating mechanisms that promote ECdriven inflammatory cell sequestration.

Besides directly impacting EC activation and survival, purigenic nucleotides can also stimulate platelet activation, leading to aggregation on vascular endothelium. ${ }^{5}$ In clinical lung transplantation, platelet accumulation has been observed and continues to be of major concern as it has been associated with primary graft dysfunction. ${ }^{25,26}$ Moreover, accumulation of activated platelets has also been reported in a rodent syngeneic lung transplantation model following prolonged cold preservation. ${ }^{27}$ Lung injury as assessed by alveolar hemorrhage and pulmonary edema correlated with the degree of intragraft platelet accumulation. Likewise, we observed alveolar hemorrhage and pulmonary edema in saline solution-treated recipients in our model of syngeneic rat lung transplantation. However, treatment at a dose of $0.66 \mathrm{mg} / \mathrm{kg}$ of APT102 was effective at preventing lung graft alveolar hemorrhage and pulmonary edema. At higher doses of APT102, however, we noted the gross appearance of intrapulmonary hematomas in some lung graft recipients upon necropsy but with no histologic evidence of bleeding into the alveoli (data not shown). In contrast, there were no intrapulmonary hematomas in lung graft recipients that received doses of APT102 of $0.66 \mathrm{mg} / \mathrm{kg}$ or less, raising the possibility that high levels of apyrase activity may prevent the platelet activation necessary for vascular repair or postsurgical hemostasis. ${ }^{28}$ Therefore, as with other agents that potentially inhibit coagulation, careful monitoring of postoperative bleeding may be required when employing apyrases to inhibit tissue inflammation in a surgical setting. Studies are now underway to examine the utility of administrating several low-dose boluses of APT102 as well altering APT102 activity by adding moieties to target fibrin deposits to catalyze the local depletion of extracellular ATP and ADP pools. It also may be possible to introduce recombinant apyrases into ex vivo lung perfusion devices; it has been recently shown that human lung grafts can be maintained for 12 hours prior to transplantation. ${ }^{29}$

Although apyrases are thought to principally reduce inflammation through attenuating EC functional responses, their effects could also be mediated through regulating myeloid cell inflammatory gene expression in lung grafts.
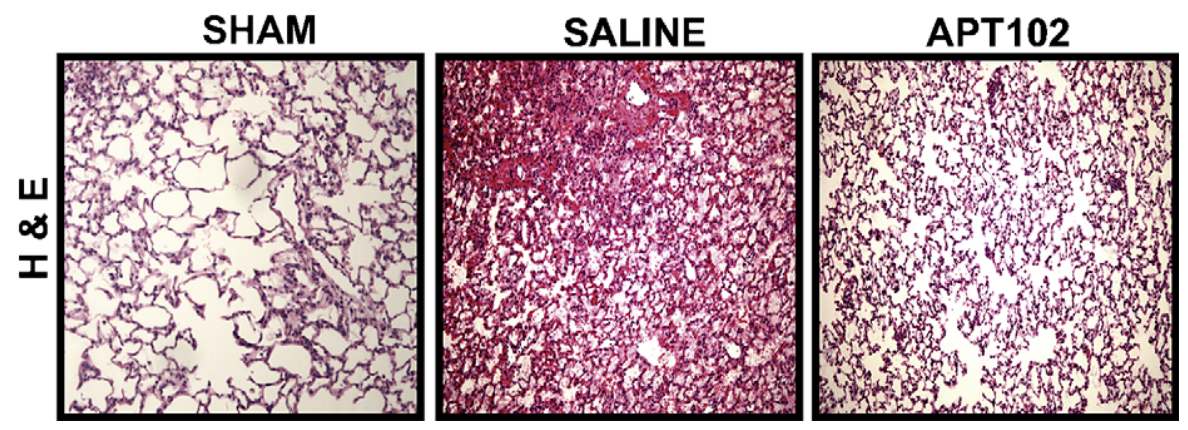

FIGURE 5. APT102 treatment improves lung graft histopathology. Lung grafts following 4 hours of reperfusion or sham lungs were fixed and sectioned for histology and stained with hemotoxylin and $\operatorname{eosin}(H \& E)$. 
A
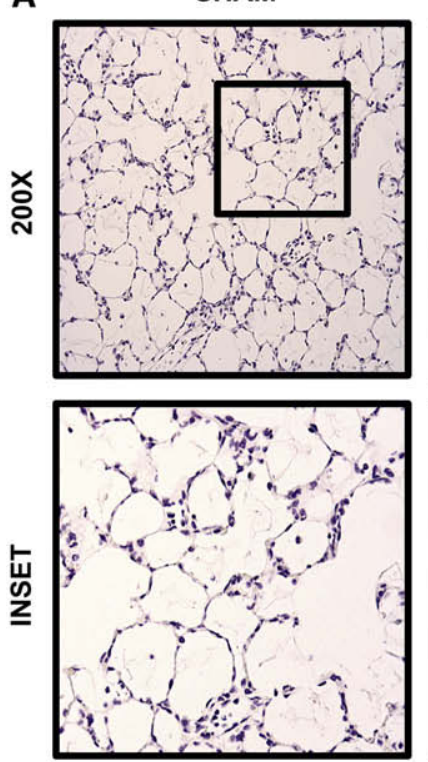

SALINE
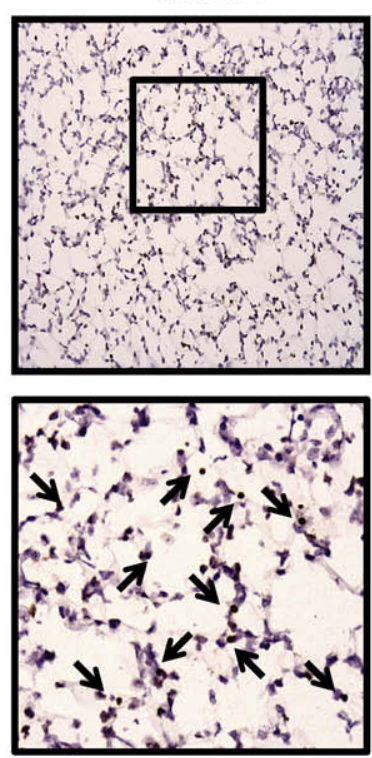

APT102
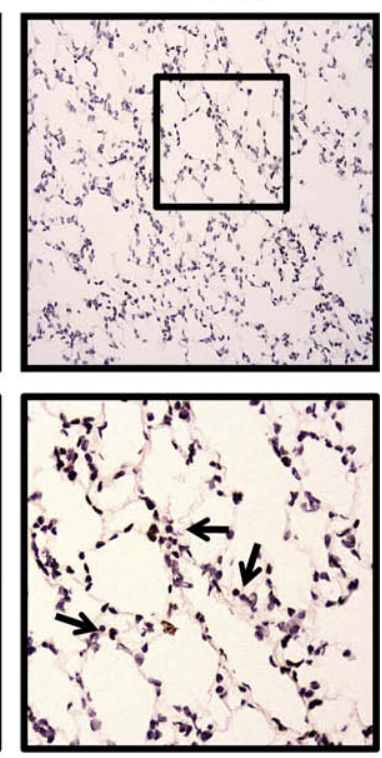

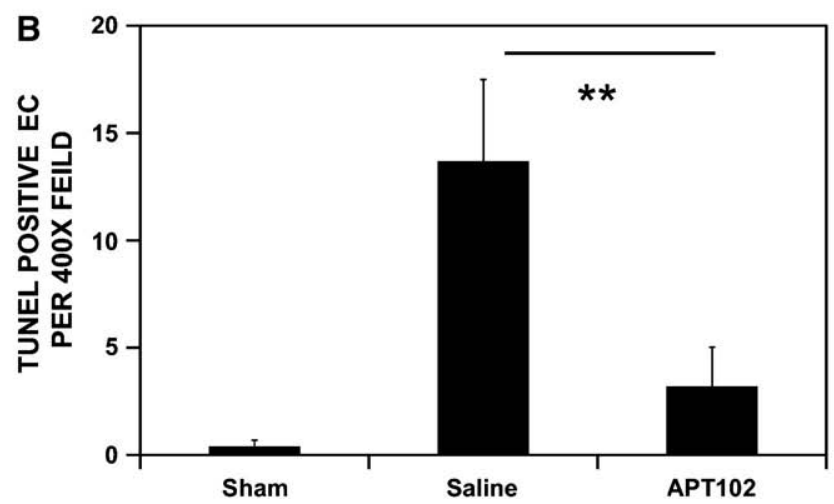

FIGURE 6. APT102 treatment attenuates lung graft endothelial cell apoptosis. Lung grafts following 4 hours of reperfusion or sham lungs were assayed for terminal deoxynucleotidyl transferase dUTP nick end labeling (TUNEL) reactivity. A, Upper panel: TUNEL-stained slides at $\times 200$ magnification with inset boxes shown in the lower panel magnified by $\times 3$. Lower panel: Examples of TUNEL-positive endothelial cells $(E C s)$ denoted with arrows. B, TUNELpositive EC nuclei were counted in randomly selected $\times 400$ fields and expressed as mean \pm standard error of the mean. $* * P<.01$ for indicated groups ( $\mathrm{n}=7 /$ group).

Engagement of purigenic receptors on monocytes and macrophages by ATP has been shown to augment IL- $1 \beta$ expression. ${ }^{8,30,31}$ Additionally, the generation of adenosine by the enzymatic degradation of ATP and ADP by apyrases may also blunt myeloid cell-dependent inflammation. Extracellular adenosine has been shown to inhibit IL-1 $\beta$ and TNF- $\alpha$ expression in macrophages through agonizing $\mathrm{A}_{2 \mathrm{~B}}$ receptors and to attenuate the oxidative burst in neutrophils via engagement of $\mathrm{A}_{2 \mathrm{~A}}$ receptors. ${ }^{32}$ Thus, the additive effect of the depletion of ATP/ADP and the concomitant generation of adenosine may synergize to blunt myeloid-dependent inflammation in lung grafts. In a model of intestinal IRI, soluble apyrase supplementation reduced injury without significantly reducing TNF- $\alpha$, IL- $1 \beta$, or MPO expression, suggesting that apyrase can mediate beneficial effects independently of regulating these genes. ${ }^{12}$ Although why apyrase treatment is more effective at reducing inflammatory mediator expression in lungs than in the intestine is not clear, one possible explanation is that intestinal bacteria enhance inflammatory gene expression that is regulated independently of ATP/ADP and adenosine, such as through tolllike receptors. ${ }^{33}$ To this end, lungs have a comparatively lower degree of bacterial colonization. Thus, the regulation of inflammatory gene expression by extracellular ATP/ ADP or the generation of free adenosine could be relatively more significant in the lung.

In summary, the present study demonstrates for the first time the beneficial effects of using a soluble apyrase to prevent lung graft IRI. These data extend previous observations on the use of apyrases in other solid organ models of IRI and suggest that apyrases inhibit inflammatory responses to lung grafts. As IRI remains an obstacle to survival in a significant 
portion of lung transplant recipients, targeting mechanisms that regulate the generation and stability of extracellular purigenic nucleotides may have clinical relevance.

\section{References}

1. Thabut G, Mal H, Cerrina J, Dartevelle P, Dromer C, Velly JF, et al. Graft ischemic time and outcome of lung transplantation: a multicenter analysis. Am J Respir Crit Care Med. 2005; 171:786.

2. de Perrot M, Liu M, Waddell TK, Keshavjee S. Ischemia-reperfusion-induced lung injury. Am J Respir Crit Care Med. 2003;167:490.

3. Morrell CN, Sun H, Swaim AM, Baldwin WM III. Platelets an inflammatory force in transplantation. Am J Transplant. 2007;7:2447.

4. De Perrot M, Sekine Y, Fischer S, Waddell TK, McRae K, Liu M, et al. Interleukin-8 release during early reperfusion predicts graft function in human lung transplantation. Am J Respir Crit Care Med. 2002;165:211.

5. Robson SC, Wu Y, Sun X, Knosalla C, Dwyer K, Enjyoji K. Ectonucleotidases of CD39 family modulate vascular inflammation and thrombosis in transplantation. Semin Thromb Hemost. 2005;31:217.

6. Gayle RB III, Maliszewski CR, Gimpel SD, Schoenborn MA, Caspary RG, Richards C, et al. Inhibition of platelet function by recombinant soluble ecto-ADPase/CD39. J Clin Invest. 1998;101:1851.

7. Koziak K, Sevigny J, Robson SC, Siegel JB, Kaczmarek E. Analysis of CD39/ ATP diphosphohydrolase (ATPDase) expression in endothelial cells, platelets and leukocytes. Thromb Haemost. 1999;82:1538.

8. Labasi JM, Petrushova N, Donovan C, McCurdy S, Lira P, Payette MM, et al. Absence of the $\mathrm{P} 2 \mathrm{X} 7$ receptor alters leukocyte function and attenuates an inflammatory response. J Immunol. 2002;168:6436.

9. Suh BC, Kim JS, Namgung U, Ha H, Kim KT. P2X7 nucleotide receptor mediation of membrane pore formation and superoxide generation in human promyelocytes and neutrophils. J Immunol. 2001;166:6754.

10. Robson SC, Kaczmarek E, Siegel JB, Candinas D, Koziak K, Millan M, et al. Loss of ATP diphosphohydrolase activity with endothelial cell activation. J Exp Med. 1997; 185:153.

11. Marcus AJ, Broekman MJ, Drosopoulos JH, Islam N, Alyonycheva TN, Safier LB, et al. The endothelial cell ecto-ADPase responsible for inhibition of platelet function is CD39. J Clin Invest. 1997;99:1351.

12. Guckelberger O, Sun XF, Sevigny J, Imai M, Kaczmarek E, Enjyoji K, et al. Beneficial effects of CD39/ecto-nucleoside triphosphate diphosphohydrolase-1 in murine intestinal ischemia-reperfusion injury. Thromb Haemost. 2004;91:576.

13. Grenz A, Zhang H, Hermes M, Eckle T, Klingel K, Huang DY, et al. Contribution of E-NTPDase 1 (CD39) to renal protection from ischemia-reperfusion injury. $F a$ seb J. 2007;21:2863.

14. Kohler D, Eckle T, Faigle M, Grenz A, Mittelbronn M, Laucher S, et al. CD39/ ectonucleoside triphosphate diphosphohydrolase 1 provides myocardial protection during cardiac ischemia/reperfusion injury. Circulation. 2007;116:1784.

15. Mizuta T, Kawaguchi A, Nakahara K, Kawashima Y. Simplified rat lung transplantation using a cuff technique. J Thorac Cardiovasc Surg. 1989;97:578.
16. Krawisz JE, Sharon P, Stenson WF. Quantitative assay for acute intestinal inflammation based on myeloperoxidase activity. Assessment of inflammation in rat and hamster models. Gastroenterology. 1984;87:1344.

17. Katayama Y, Hidalgo A, Chang J, Peired A, Frenette PS. CD44 is a physiological E-selectin ligand on neutrophils. J Exp Med. 2005;201:1183.

18. Okazaki M, Kreisel F, Richardson SB, Kreisel D, Krupnick AS, Patterson GA et al. Sphingosine 1-phosphate inhibits ischemia reperfusion injury following experimental lung transplantation. Am J Transplant. 2007;7:751.

19. Okazaki M, Gelman AE, Tietjens JR, Ibricevic A, Kornfeld CG, Huang HJ, et al. Maintenance of airway epithelium in acutely rejected orthotopic vascularized mouse lung transplants. Am J Respir Cell Mol Biol. 2007;37:625.

20. Quadri SM, Segall L, de Perrot M, Han B, Edwards V, Jones N, et al. Caspase inhibition improves ischemia-reperfusion injury after lung transplantation. Am J Transplant. 2005;5:292.

21. Ishiyama $\mathrm{T}$, Dharmarajan $\mathrm{S}$, Hayama $\mathrm{M}$, Moriya $\mathrm{H}$, Grapperhaus $\mathrm{K}$, Patterson GA. Inhibition of nuclear factor kappaB by IkappaB superrepressor gene transfer ameliorates ischemia-reperfusion injury after experimental lung transplantation. J Thorac Cardiovasc Surg. 2005;130:194.

22. von Albertini M, Palmetshofer A, Kaczmarek E, Koziak K, Stroka D, Grey ST, et al. Extracellular ATP and ADP activate transcription factor NF-kappa B and induce endothelial cell apoptosis. Biochem Biophys Res Commun. 1998;248:822.

23. Goepfert C, Imai M, Brouard S, Csizmadia E, Kaczmarek E, Robson SC. CD39 modulates endothelial cell activation and apoptosis. Mol Med. 2000;6:591.

24. Demertzis S, Langer F, Graeter T, Dwenger A, Georg T, Schafers HJ. Amelioration of lung reperfusion injury by L- and E- selectin blockade. Eur J Cardiothorac Surg. 1999;16:174.

25. Sternberg DI, Shimbo D, Kawut SM, Sarkar J, Hurlitz G, D’Ovidio F, et al. Platelet activation in the postoperative period after lung transplantation. $J$ Thorac Cardiovasc Surg. 2008; 135:679.

26. Shargall Y, Guenther G, Ahya VN, Ardehali A, Singhal A, Keshavjee S. Report of the ISHLT Working Group on Primary Lung Graft Dysfunction part VI: treatment. J Heart Lung Transplant. 2005;24:1489.

27. Okada Y, Marchevsky AM, Zuo XJ, Pass JA, Kass RM, Matloff JM, et al. Accumulation of platelets in rat syngeneic lung transplants: a potential factor responsible for preservation-reperfusion injury. Transplantation. 1997;64:801.

28. Uluckan O, Eagleton MC, Floyd DH, Morgan EA, Hirbe AC, Kramer M, et al APT102, a novel adpase, cooperates with aspirin to disrupt bone metastasis in mice. J Cell Biochem. 2008;104:1311.

29. Cypel M, Yeung JC, Hirayama S, Rubacha M, Fischer S, Anraku M, et al. Technique for prolonged normothermic ex vivo lung perfusion. J Heart Lung Transplant. 2008;27:1319.

30. Griffiths RJ, Stam EJ, Downs JT, Otterness IG. ATP induces the release of IL-1 from LPS-primed cells in vivo. J Immunol. 1995;154:2821.

31. Sipka S, Kovacs I, Szanto S, Szegedi G, Brugos L, Bruckner G, et al. Adenosine inhibits the release of interleukin-1beta in activated human peripheral mononuclear cells. Cytokine. 2005;31:258.

32. Linden J. New insights into the regulation of inflammation by adenosine. J Clin Invest. 2006;116:1835.

33. Kopp E, Medzhitov R. Recognition of microbial infection by Toll-like receptors. Curr Opin Immunol. 2003;15:396. 